\title{
NOTAS \\ LA VOZ DE MÉXICO: APUNTES SOBRE EL DEUM
}

La publicación de este Diccionario del español usual en México* es un acontecimiento especialmente emotivo para mí, puesto que, por primera vez, siento que tengo en mis manos la voz de México. Al recorrer sus páginas, puedo oír hablar a mis colegas y amigos, a mis hijas, a la gente a mi alrededor. He visto cómo un hablante del español de México lee las entradas, las acepciones, los ejemplos, asintiendo silenciosamente con la cabeza hasta soltar una risa de gozo y decir “¡sí es cierto, así hablamos!”. Y ya he oído contar cómo un grupo de amigos puede sentarse durante horas a leer y comentar sus páginas. En las líneas que siguen, analizo el DEUM, hago sugerencias, apunto errores, todo con la esperanza de contribuir a mejorarlo aún más. Pero nada de lo que digo debe opacar el hecho principal: es una obra imprescidible para cualquier persona o institución que tenga interés en el español de México, sea mexicano o extranjero, adulto o joven, académico, hombre de negocios o trabajador manual.

Este diccionario es el tercero, y penúltimo, programado en la construcción de un diccionario del español de México (DEM), proyecto iniciado hace veinticuatro años en El Colegio de México bajo la dirección de Luis Fernando Lara ${ }^{1}$ La primera versión, el

* Dirigido por L. F. Lara; G. Anguiano Peña, A. Díez-Canedo, L. Fernández Gordillo, F. Segovia, L. Sosa Pedroza, C. D. Valadez y C. Villanueva (equipo lexicográfico); con otros colaboradores, El Colegio de México, México, 1996.

${ }^{1}$ Durante la presentación del DEUM, celebrada el 15 de enero de 1997 en El Colegio de México, más de una persona se refirió al cuarto producto del DEM como si fuera el último. En mi opinión, es un proyecto que debería ser permanente, como otros grandes proyectos lexicográficos, para seguir aprovechando los materiales y la experiencia ya acumulados, para sacar a la luz más productos, así como para realizar investigaciones adicionales en cuanto al léxico del español de México. Con los recursos informáticos ya disponibles y la existencia de mu- 
Diccionario fundamental del español de México ${ }^{2}$ tenía apenas 2500 palabras y 15000 acepciones; la segunda, el Diccionario básico del español de México ${ }^{3}$, tenía 7000 entradas y 40000 acepciones; y ésta, el DEUM, tiene 14000 entradas y 100000 acepciones (incluyendo 40000 locuciones o frases fijas). Si el primero fue un bebé en pañales, y el segundo un mero niño, este tercer diccionario es un joven todavía imberbe, pero ya manifiesta su personalidad de adulto. Es un diccionario innovador y de mucho interés teórico y metodológico ${ }^{4}$. Pero este mismo hecho le da también algunas características peculiares que lo hacen, más que un diccionario, una muestra del léxico del español de México. Los usuarios que esperan un diccionario común y corriente que pueda competir con los diccionarios comerciales más conocidos quedarán decepcionados si no entienden bien este punto.

El proyecto del DEM es casi único en su meta principal: construir un diccionario original de la lengua española tal como se maneja, en todos sus niveles, en un lugar específico (en este caso México). Es una meta muy meritoria; sólo cuando exista este tipo de estudios de varios puntos representativos del mundo hispanoparlante se podrá intentar construir un verdadero diccionario del español general o internacional y no un diccionario necesariamente sesgado por la Península ibérica y la (excelente) tradición lexicográfica fincada ahí. Esto implica construir una nomenclatura nueva a partir de la lengua mexicana y no a partir de la de otros diccionarios. También implica la redacción de nuevas definiciones, y no la práctica consagrada entre los lexicógrafos de simple-

chos libros y periódicos en forma electrónica, sería factible, por ejemplo, iniciar un tipo de vigilancia léxica continua que cotejaría textos nuevos con la base de datos del $D E M$, registraría formas que no están allí y proporcionaría al equipo lexicográfico una fuente inagotable de materiales para analizar y para incorporarlos en nuevas ediciones de sus diccionarios.

${ }^{2}$ L. F. Lara et al., Diccionario fundamental del español de México, Comisión Nacional para la Defensa del Idioma Español-El Colegio de México-F.C.E., México, 1982.

${ }^{3}$ L. F. LaRa et al., Diccionario básico del español de México, El Colegio de México, México, 1986.

${ }^{4}$ Véanse L. F. Lara, R. Ham Chande y M. I. García Hidalgo, Investigaciones lingüisticas en lexicografia, El Colegio de México, México, 1979; L. F. Lara, Dimensiones de la lexicografía. A propósito del "Diccionario del español de México", El Colegio de México, México, 1990; y Teoría del diccionario monolingüe, El Colegio de México, México, 1997 para una descripción más detallada de todo lo que hay atrás de este proyecto. 
mente copiar - a veces con modificaciones, a veces no- las definiciones de sus predecesores.

Para resolver el problema de cómo establecer el español de México, los investigadores del DEM han rechazado, por lo menos como recurso de primera instancia, el uso de sus propias intuiciones como hispanohablantes. Desde un principio han trabajado a partir de un corpus, de dos millones de palabras formado por mil textos de dos mil palabras cada uno, de varios géneros, escritos y hablados, del español mexicano producido entre 1921 y 1974. El DEUM contiene todo vocablo con una frecuencia de por lo menos diez ocurrencias en este corpus, incrementado por algunas palabras importantes en la enseñanza escolar en México "para la correcta comprensión de la historia, de las ciencias, de las técnicas y de las leyes" (p. 13), por palabras que fueron utilizadas en la redacción de las definiciones ( $d e-$ finientes) pero que de otra manera no hubieran sido incluidas, y por algunas palabras más que se decidió agregar por representar huecos importantes en el corpus ${ }^{5}$. Desafortunadamente, las palabras que no provienen del corpus no se identifican. Una manera de hacerlo, que al mismo tiempo comunicaría algo de la riqueza de información estadística que ha generado el proyecto, sería registrar la frecuencia de cada entrada obtenida en el corpus. Así, el lector sabría que las palabras con una frecuencia menor de diez habrían sido agregadas por algún motivo.

El lugar central de un corpus en la confección del diccionario es tanto su piedra angular cuanto su talón de Aquiles. De un lado, le proporciona el DEUM un aspecto descriptivo laudable y garantiza que el contenido sea auténticamente mexicano. Pero, de otro, excluye en principio cualquier palabra que no esté en el corpus, aun cuando sea palabra bien conocida y frecuente en el español de México. Tal es el caso de la palabra guacamole, por ejemplo, que no aparece en el corpus, pero que no por eso debe estar excluida del diccionario ${ }^{6}$. Esto quiere decir que el equipo lexicográfico del DEM debería emplear otras técnicas para completar su nomenclatura $^{7}$; de otra manera, su diccionario estará condenado a sufrir

${ }^{5}$ Miembros del equipo me informan que el número de palabras agregadas a la nomenclatura y que no forman parte del corpus no rebasa el cinco o diez porciento del total.

${ }^{6}$ De hecho, éste es un ejemplo de las palabras que los editores han incluido en el diccionario por representar una laguna desafortunada en el corpus.

${ }^{7}$ Por ejemplo, utilizar los materiales del proyecto del Atlas lingüistico de México, también de El Colegio de México dirigido por Juan M. Lope Blanch (cf. t. 1: Fonética, El Colegio de México-F.C.E.-UNAM, México; y J. G. Moreno de Alba, 
ausencias embarazosas para siempre. Por el momento, empero, el proyecto tiene más que suficiente trabajo para simplemente terminar con el corpus que tiene en las manos. Contempla incluir cada vocablo con un mínimo de tres ocurrencias en el corpus, ¡lo cual implica la inclusión de aproximadamente veinte mil palabras adicionales en la cuarta versión! ${ }^{8}$.

Las limitaciones impuestas por un corpus cerrado y por ser un proyecto aún inconcluso hacen afirmar que este dicccionario es más afín a un florilegio de la lengua española mexicana que a un diccionario donde uno puede encontrar todo lo usual en el habla de México ${ }^{9}$. Hay un amplio número de ausencias muy notorias. Para nombrar algunas: achichincle, aerobics, aguayón, albur, antro, arroba, ateneo, azabache, bacha, bache, baro, bofo, bye/bay, cachirul, cancel, candelaria, canje, caset, core (< inglés quarterback), cotija, chambelán, champurrado, chanfle, changarro, chatarra, chela, choro, chota, chuza, decimonónico, desmadre, despistado, difrasismo, disímbolo, disquet, dos ${ }^{10}$,

La pronunciación del español en México, El Colegio de México, México, 1994), algunos de los cuales formaron parte del corpus; utilizar los materiales contenidos en estudios especializados del español de México (por ejemplo, R. Ávila, El habla de Tamazunchale, El Colegio de México, México, 1990; B. Garza Cuarón, El español hablado en la ciudad de Oaxaca, México (caracterización fonética y léxica), El Colegio de México, México, 1987; y R. Williamson, El habla de Tabasco. Estudio lingüístico, El Colegio de México, México, 1986); aprovechar los estudios de disponibilidad léxica que han sido realizados en México (cf. J. López Chávez y E. NuñEz Alonso, Léxico disponible de sexto grado de primaria, UNAM, México, 1993, por ejemplo); incluir palabras o significados que se pueden documentar en fuentes publicadas de cierto tipo, número y distribución; construir corpora adicionales para ciertos géneros, períodos o especialidades, etc. El equipo lexicográfico me informa que, de hecho, el acervo de información del proyecto incluye mucho material de este tipo ya fichado e incorporado en la documentación de palabras que no forma parte del corpus. Tomarán en cuenta estos vocablos adicionales para hacer la selección final de la nomenclatura que incluirán en la próxima versión.

${ }^{8}$ Me informan que ya tienen estas nuevas entradas en una primera redacción, aunque todavía falta la etapa de corrección. También están trabajando en las palabras de una o dos ocurrencias en el corpus para aumentar el acervo léxico total del proyecto y, al considerarlo oportuno, introducir algunas de ellas en la próxima versión.

${ }^{9}$ Esta opinión es una exageración, por supuesto, pero con ella quisiera subrayar la sensación de que es incompleto como diccionario, aun cuando rebasa por mucho un simple florilegio léxico.

${ }^{10}$ Esta palabra fue excluida conscientemente como los otros números, puesto que éstos aparecen en un cuadro especial al final de la obra. Las únicas excepciones son los números que tienen alguna acepción adicional a la numérica o que aparecen en alguna locución que convendría incluir. No estoy de acuer- 
edecán, edil, esculcar, estudiantina, fax, fotocopia, fuchi, g(u)iga/yiga (prefijo métrico), happy, hemeroteca (y otras varias -tecas), huácala, huácara, huevón, jaripeo, $k / k a(<$ kilobyte[s]), labia, liceo, ma, machote, mamotreto, manchego, matasellos, membresía, mocho, nevada, nosocomio, oink, ombliguera, ovni, pa, pandroso, paracaidista, pastorela, pichancha, pidgin, plafón, pompi/pompa, porfa, pretil, quisquilloso, quorum/cuórum, rasta, reseña, seta, solideo, suadero, talacha, timbiriche, títere, toloache, tomblin, trailer, trajinera, tris, tromba, unicel ${ }^{11}$, vulcanizador, wow/guau. Algunos comentaristas ya han visto en este tipo de ejemplos un defecto grave. Pero, repito, sólo lo es para los que no entienden bien lo que es el DEUM. La misma Introducción debe alertar al usuario sobre este fenómeno, pero, desgraciadamente, no lo hace.

Cabe señalar que el DEUM, por su parte, incluye varias palabras que no se encuentran fácilmente en otros diccionarios. Por ejemplo, una revisión de las aproximadamente ciento cincuenta entradas bajo la letra $c h^{12}$ revela siete (el cinco por ciento) que no se encuentran en diccionarios generales como el de la Real Academia Española (1992 [DRAE]) o El pequeño Larousse (1996) [Larousse]), ni tampoco en el importante Diccionario de mejicanismos de F. J. Santamaría13: chalán (tipo de embarcación), chale (interjección), chavo, che (argentino), chetumalense, chido, chin. El DRAE y el Larousse no tienen chañabal, charanda, chichi, chingadazo, chingado; y chalán (ayudante de albañil), chamula, chance, checar, chef, chicuelina y chingada están ausentes del DRAE. En otras letras, se encuentran palabras como bilet, bisectar, bisquet, estafiate, fílum, financiera, guayín, güey, hippie, histopatología, hit y hockey que no están incluidas en el DRAE.

do con esta decisión, que de todas maneras debiera haber sido mencionada en la Introducción. Todos los términos básicos del sistema de numeración deben aparecer en la nomenclatura.

${ }^{11}$ Los editores han excluido, por razones legales, las palabras, como kleenex, kotex y ésta, que representan marcas registradas ya convertidas en términos genéricos, aunque sí incluyen crayola. Cabe reflexionar sobre este problema y hasta qué punto la sociedad debe permitir que se legisle su lengua y los diccionarios que la recogen.

12 El DEUM ha continuado la muy respetable práctica establecida por Nebrija de tratar la $c h$ como letra aparte del alfabeto del español, a pesar de la moda actual de doblegarse ante las presiones internacionales y tratarla como una secuencia de $c$ más $h$, en lugar de exigirles a los profesionales de la informática que nos proporcionen programas de ordenación que permitan definir el orden y las unidades con los cuales deben operar.

$133^{a}$ ed., Porrúa, México, 1978 [1ª ed., 1959]. 
Fue meta de los autores del DEUM "redactar las definiciones con las palabras más sencillas que se encuentren y que éstas formen parte del Diccionario" (p. 17), pero es muy fácil encontrar contraejemplos. Cf., por ejemplo, alabeo (bajo alabeado), baloncesto (bajo basquetbol), benjui (p. 33), boñiga (bajo raja), brahman (bajo hinduismo), cacahuazintle (bajo pozole), capelo (bajo píleo), cícero (bajo cuadratín), cordonazo (bajo canicula), corpus (p. 13), látex (bajo hule), lona (bajo mochila), papadzul (bajo indigenismo), pápalo (bajo papaloquelite), Pascua de cordero (bajo Pentescostés), pellizcar (bajo pizzicato), quenopodiácea (bajo romeritos), santoraly santoniño (bajo santo), verga (bajo mamar), vilo (bajo cargar), xocoyotey herrar (p. 31) ${ }^{14}$. Los editores están conscientes de este problema y me informan que están preparando un programa de computadora para poder identificar y luego corregir casos como éstos para la próxima versión. Al respecto, es interesante notar que el Diccionario para la enseñanza de la lengua española ${ }^{15}$ incluye, al final (pp. 1237-1248), una lista de alrededor de dos mil palabras que son las que han sido utilizadas para redactar sus definiciones. Sería interesante ver una lista semejante para el DEUM.

Otro aspecto importante de este diccionario son las definiciones. Para cumplir con sus objetivos y evitar el lastre típico de otros diccionarios que muchas veces repiten las definiciones de sus antecesores, el equipo encargado del DEUM ha redactado todas sus definiciones de nuevo, a partir de su corpus, pero, claro, tomando en cuenta otras fuentes también. Se ha esmerado en particular en producir definiciones con lenguaje sencillo y evitar las definiciones circulares lo más posible. En general, me parece que ha tenido un éxito rotundo. Las definiciones son claras y fáciles de entender. Emplea definientes conocidos y usuales en México y evita remisiones innecesarias a entradas en otras partes del diccionario. También enfoca su atención en los usos de las palabras más típicas en México. Por lo tanto, no deben espantar o confundir demasiado a los estudiantes y adultos que tienen poca experiencia en la con-

${ }^{14}$ Algunos de estos ejemplos no vienen de las definiciones, sino de las preliminares o de los ejemplos, pero me parece igualmente importante que la nomenclatura incluya este tipo de palabras también. El equipo tomó una decisión consciente de excluir algunos definientes por ser poco usuales o por no cargar la nomenclatura con demasiados términos técnicos. Sin embargo, si una palabra es suficientemente importante como para mencionarla o usarla en el diccionario, entonces merece tener una entrada propia.

${ }^{15}$ Dirigido por M. Alvar EzQuerra y editado por Vox-Universidad de Alcalá de Henares, Barcelona-Alcalá de Henares, 1996. 
sulta de un diccionario. Para apreciar lo anterior, comparemos algunas entradas del DEUM con las de otros tres diccionarios utilizados en México: el Diccionario Porrúa ${ }^{16}$, El pequeño Larousse y el $D R A E$ (en las ediciones que ya he citado).

\section{Diccionario Porrúa}

azolvar tr. y $r$. Cegar o tupir un conducto.

azotea $f$. Cubierta llana de un edificio, dispuesta para poder andar por ella. Terraza, solana.

cimbra $f$. Armazón de maderos sobre el que van colocándose las dovelas de una bóveda o arco hasta dejarlos cerrados. Vuelta o curvatura de la superficie interior de un arco o bóveda.

cimbrar tr. $y r$. Mover una vara larga $\mathrm{u}$ otra cosa flexible asiéndola por un extremo y vibrándola. Colocar las cimbras en una obra.

criba $f$. Cerco con tela para cribar. Arnero, tamiz, cedazo.

cribar $t r$. Limpiar semillas por medio de la criba. Pasar semillas o minerales por la criba, para separar las partes menudas.

sotavento $\mathrm{m}$. Costado de la nave opuesto al barlovento. Parte que cae hacia aquel lado.

\section{Larousse}

azolvar v. tr. pron. [1] Cegar un conducto.

azotea n. f. Cubierta llana de un edificio por la cual se puede andar. cimbra n. f. Curvatura interior de un arco o de una bóveda. 2. Armazón que sostiene las dovelas de un arco o de una bóveda durante su construcción. - Plena cimbra, cimbra que forma un semicírculo.

cimbrar o cimbrear v. tr. y pron. [1]. Imprimir movimiento vibratorio a un objeto largo, delgado y flexible, que está sujeto por un extremo. 2. Fig. Mover el cuerpo o una parte de él con garbo y soltura. 3. Colocar las cimbras en una obra.

criba n. f. Instrumento para cribar, compuesto por un cerco al cual está asegurado un cuero agujereado o una tela metálica. 2. Fig. Medio de seleccionar y, en particular, de distinguir lo verdadero o bueno de lo que no lo es: pasar por la criba de la crítica. 3. BOT. Tabique perforado, transversal u oblicuo, de los vasos cribosos. • Criba de Eratóstenes, método que permite establecer una tabla de números primos.

cribar v. tr. (lat. cribare) [1]. Pasar una semilla o un mineral por la criba, para limparlo de impurezas o separar las partes menudas de las gruesas.

16 A. Raluy Poudevida y F. Monterde, Diccionario Porrúa de la lengua española, 26a ed., Porrúa, México, 1986 [ed. original, 1969]. 
sotavento n. m. Costado de la nave opuesto al barlovento. 2. Parte que cae hacia aquel lado.

$D R A E$

azolvar. (Del ár. aś-śulba, la obstrucción, la detención.) tr. Cegar o tupir con alguna cosa un conducto. Ú. t. c. prnl.

azotea. (Del ár. as-sut́aih́a, el terradillo.) f. Cubierta llana de un edificio, dispuesta para poder andar por ella.

cimbra. (De or. inc.; cf. cat. cíndria.) f. Arq. Armazón que sostiene el peso de un arco o de otra construcción, destinada a salvar un vano, en tanto no está en condiciones de sostenerse por sí misma. II 2. Arq. Vuelta o curvatura de la superficie interior de un arco o bóveda. II 3. Mar. Vuelta o curvatura que se obliga a tomar a una tabla, para colocarla y clavarla en su lugar en el forro de un casco. II plena cimbra. La que forma un semicírculo.

cimbrar. (De cimblar.) tr. Mover una vara larga u otra cosa flexible, asiéndola por un extremo y vibrándola. Ú. t. c. prnl. II 2. fig. y fam. Dar a alguien con una vara o palo, de modo que le haga doblar el cuerpo. II 3. Doblar o hacer vibrar una cosa. Ú. t. c. prnl. II 4. Mover con garbo el cuerpo al andar. Ú. m. c. prnl. ॥ 5. Arq. Colocar las cimbras en una obra.

criba. (De cribo.) f. Cuero ordenadamente agujerado y fijo en un aro de madera, que sirve para cribar. También se hacen de plancha metálica con agujeros, o con red de malla de alambre. I| 2. Cualquiera de los aparatos mecánicos que se emplean en agricultura para cribar semillas, o en minería para lavar y limpiar los minerales. II 3. Bot. Cualquiera de los tabiques membranosos, transversales u oblicuos, situados en el interior de los vasos cribosos de las plantas y que tienen pequeños orificios por los que pasa la savia descendente. II estar una cosa como una criba, o hecha una criba. fr. fig. y fam. Estar muy rota y llena de agujeros. cribar. (Del lat. cribrãre.) tr. Limpiar el trigo u otra semilla, por medio de la criba, del polvo, tierra, neguilla y demás impurezas. II 2. Pasar una semilla, un mineral u otra materia por la criba para separar las partes menudas de las gruesas.

sotavento. (Del lat. subtus, debajo, y ventus, viento.) m. Mar. Costado de la nave opuesto al barlovento. II 2. Mar. Parte que cae hacia aquel lado.

DEUM

azolvar v tr (Se conjuga como amar) 1 Tapar u obstruir lodo o basura algún conducto o canal, de modo que impide el paso del agua 2 Depositar las corrientes marinas o fluviales arena y otros materiales en el fondo, disminuyendo su profundidad. 
azotea s f I Techo aplanado por el exterior que sirve como último piso de una casa o edificio; generalmente se encuentran en él los tinacos y se usa para tender la ropa lavada; sobre ella se construyen cuartos en los que por lo general habita la servidumbre II (Popular) Cabeza: “¡Cuidado con la azotea! ¡No te vayas a dar un tope!”.

cimbra s f 1 Armazón o molde de madera, de fierro u otros materiales sobre el que se lleva a cabo el colado de concreto o cemento de un techo o una bóveda y que se retira una vez que ha fraguado y endurecido 2 Aparejo de pesca que consta de un madero grande al que se amarra el anzuelo, usado para pescar tiburón en el Pacífico.

cimbrar $^{1} \mathrm{v}$ tr (Se conjuga como amar) Colocar las cimbras en una construcción: "La obra estaba detenida por falta de madera para cimbrar".

cimbrar $^{2} \mathrm{v}$ tr (Se conjuga como amar) Hacer que algo rígido vibre: "La explosión cimbró todo el edificio", "Cuando pasan los trenes, el piso se cimbra fuertemente".

criba s f Utensilio con que se limpia de impurezas la semilla, los minerales, etc, hecho a base de un cuero o una tela agujereados, de acuerdo con el tamaño de los objetos que se desea dejar pasar.

cribar $\mathrm{v}$ tr (Se conjuga como amar) 1 Hacer pasar trigo o alguna otra semilla por una criba para limparlos de ramas, hojas, etc $\mathbf{2}$ Hacer pasar algún material por una malla fina, para limpiarlo de impurezas o para seleccionar su tamaño.

sotavento s m 1 Lado opuesto a aquel de donde viene el viento que recibe una embarcación o un lugar cualquiera: la vertiente del sotavento de la Sierra Madre 2 Lado de la embarcación opuesto al del viento.

Todos los diccionarios, con la excepción del DEUM, utilizan cribar en su definición de criba, y criba en su definición de cribar. Aunque no siempre crea una circularidad viciosa, sí es una práctica evitada a propósito en el DEUM. También se puede notar cómo los editores han dado usos, materiales, ejemplos, etc., que sirven para evocar la visión de la palabra que rige en México, aun cuando el significado stricto sensu no sea diferente. Esta característica se nota en especial al comparar las definiciones de azotea. En los otros diccionarios, las definiciones de sotavento ilustran el problema de requerir una búsqueda adicional para entender el significado de una palabra puesto que es probable que alguien que no entiende sotavento tampoco entenderá barlovento. Finalmente, se nota en el caso de azolvar, cimbra y cimbrar que el uso que se da a estos tér- 
minos en México es algo distinto, por lo menos en términos de sus significados prototípicos, del que registran los otros diccionarios.

Es particularmente gratificante encontrar definientes que pertenecen a la lengua usual de los mexicanos. El contraste con los que se encuentran en el DRAE es, a veces, muy marcado. Volviendo a los ejemplos anteriores, la definición que dan los otros diccionarios de azolvar en términos de cegar y tupir corresponde en parte con la mexicana, pero aquí resulta mucho más claro decir tapar y obstruir. La definición del DRAE para champú como "loción para el cabello" no se entiende en México; es hasta buscar loción y descubrir que es un "producto preparado para la limpieza del cabello" que el lector da cuenta del verdadero significado. Y la definición del DRAE para chaparreras como "especie de zahones de piel adobada" obliga al lector mexicano a buscar zahón y adobado para entenderla plenamente. Tampoco encontramos remisiones ridículas (desde la perspectiva del español de México, por supuesto) como la del DRAE que, bajo chilacayote, manda al lector a leer la entrada de cidra cayote.

Las definiciones de plantas y animales me parecen especialmente apropiadas. Los editores no caen en la trampa de definir una especie por medio de su nombre científico, pero sí lo proporcionan para las especies más típicas de México cuando lo han podido establecer. Esta práctica ayuda a buscar información más completa en obras técnicas si así quiere el lector. Tampoco dan definiciones tan técnicas que sólo un especialista las pueda entender. Se enfocan en las características, los usos, y el comportamiento por los cuales se conocen entre la población general de México. Véase, como ejemplo, la definición siguiente de huauzontle:

huauzontle s m (Chenopodium bonus hemicus) Planta herbácea de hojas alternas ovadas y flores verdosas pequeñísimas, amontonadas en panículas; las flores son comestibles y se preparan capeadas con huevo en tortas, rellenas de queso y embebidas en caldillo de jitomate y salsa de chile; guauzontle, huazontli.

No quiero decir con lo anterior que siempre estoy de acuerdo con las definiciones. He aquí algunas que me han llamado la atención: $a$ ) para colegio el DRAE dice que es un "Establecimiento dedicado a la enseñanza o al estudio". Es una definición correcta, pero no hay nada que indique que comúnmente, por lo menos en el Distrito Federal, se usa para una escuela de enseñanza básica y 
de paga ${ }^{17} ; b$ ) la redacción de la definición de cocoa me parece confusa e incorrecta o, por lo menos, incompleta: "Polvo de chocolate semidescremado, generalmente de productos importados de los Estados Unidos de América". Decir que se hace de chocolate implica que tiene azúcar y no la tiene. Decir que es descremada implica que tiene leche o crema y no la tiene. En su forma común, que se usa para repostería, es un polvo hecho de cacao molido una vez quitada gran parte de su manteca; $c$ ) para la segunda acepción de hindú se dice "indio", pero al consultar la entrada de indio, se puede pensar que es "que desciende de los habitantes originarios de América". Sería menos ambiguo decir "de la India" o indicar a cuál de las acepciones de indio se refiere, como se hace en otros casos paralelos ${ }^{18}$; d) la acepción VI, 3, de bueno dice “¡Diga!, ¡lo escucho!, al hablar por teléfono”. No es una definición, sino una lista de alternativas. Yo preferiría algo como "Palabra que se utiliza al contestar el teléfono para indicar que se está preparado para escuchar a la persona que está llamando, o cuando hay dudas sobre la presencia del interlocutor o su capacidad para escuchar, para ver si contesta"; e) para indígena, sólo da la acepción general de "que nació o tuvo su origen en la tierra, la región o el país del que se trata; que se relaciona con los pueblos y las culturas originarias de un lugar". No hay nada que indique que se utiliza frecuentemente sin calificación para referirse específicamente a indígenas americanos o mexicanos; $f$ ) la segunda acepción de mochila se refiere a una bolsa usada por los escolares, sin notar que, normalmente, está diseñada para ser llevada en la espalda. También me parece aconsejable, cuando se dan los materiales con que se hace algo como parte de su definición, calificar la lista con algún término como comúnmente o generalmente, excepto cuando el material en realidad sea parte de la definición. De hecho, así se hace en el $D E U M$ en muchos casos, pero para la primera acepción de mochila, se dice que es una "bolsa amplia de lona, cuero o plástico que se carga en la espalda", sin tal calificación; $g$ ) en la definición de claxon, hace falta el propósito, generalmente para avisar, llamar la atención, o quejarse. Este sí se da en la acepción correspondiente de bocina; $h$ ) se dice que el ala de ángel (bajo ala) "crece en

17 Es cierto que en los subtítulos de películas es relativamente común ver que se traduce college del inglés como colegio, pero siempre me ha parecido una mala traducción; universidad es más apropiado.

${ }^{18} \mathrm{Cf}$., por ejemplo, huautli, donde se remite a alegría ${ }^{2}$, es decir, la segunda aparición de alegría en la nomenclatura. 
lugares húmedos y sombreados", pero también es común en el parque ecológico del Ajusco, en lugares pedregosos, secos y expuestos al sol. La altura de un metro que se da para esta planta me parece exagerada (o quizás un máximo, pero no un promedio), puesto que los ejemplares que conozco tendrán unos 75 centímetros; $i$ ) se dice que el ladrillo es de forma prismática, pero tal caracterización es demasiado vaga. Normalmente es un paralelepípedo rectángulo, por lo menos en los casos que yo he visto; $j$ ) en la acepción II de raiz, que se le atribuye a la gramática, se dice que es un "lexema", pero éste es un término muy marcado teóricamente mientras que raíz es mucho más neutral. El significado de raíz no debe depender del de lexema. Sería mejor definirla directamente como "la parte de una palabra que expresa su significado básico y que no puede ser analizada en partes menores". Tampoco me convence la acepción matemática III, 1, de esta palabra como una "operación". Su sentido más inmediato para mí es el de un número que resulta de cierta operación (la radicación). Si en realidad raíz se puede usar para la operación en sí (mis hijas me aseguran que sí), se deben buscar mejores ejemplos que más claramente se refieran a ella, quizás algo como "estoy bien con las sumas pero las raíces me causan muchos problemas" o "esta calculadora tiene logaritmos pero no hace raíces" o "puso cinco raíces en el examen"; $k$ ) cuando fresa se refiere a un joven, el DEUM dice que indica "que no participa en reuniones en que se fume mariguana, se consuman drogas o se beba mucho; que no se arriesga a contravenir normas y leyes", pero creo que más bien sería un joven de familia adinerada preocupado por verse bien y tener un estatus social que responda a las reglas del consumismo. Un joven pobre, humilde, mocho y convencional, no es por eso muy fresa; $l$ ) en las entradas de cuadrado, cubo y potencia, se debe indicar la manera de expresar un número elevado al cuadrado, al cubo, o a cierta potencia. Por ejemplo, podrían incluirse ejemplos como los siguientes: 10 al cuadrado se representa como $10^{2}$ y es igual a $10 \times 10=100 ; 2$ a la quinta potencia se representa como $2^{5}$ y es igual a 2 × 2 × 2 × 2 × $2=32$. Además, se debe dar ejemplos de cómo se leen expresiones como $10^{2}$ y $5^{3} ; \mathrm{m}$ ) las definiciones de las estaciones del año (verano, otoño, invierno, primavera) están expresadas en términos de períodos de tiempo, pero no mencionan el movimiento de la Tierra alrededor del Sol, o el movimiento aparente del Sol en el horizonte, en que se basan. Reflejan, además, una visión de cambios ambientales inapropiada en ciertas partes de México, donde no hay cambios bruscos de temperatura y don- 
de el cambio estacional más importante es la presencia o ausencia de lluvia. Por ejemplo, hay lugares como Yucatán y Chiapas (por lo menos históricamente; no estoy seguro de la situación contemporánea) donde la palabra invierno se refiere a la época de lluvias, aproximadamente desde junio hasta octubre, y verano a la época de secas. Y la época cuando aparecen más flores en el Distrito Federal parece ser el otoño más que la primavera. La caracterización que da el DEUM de primavera como "la estación en la que florecen las plantas" refleja un ámbito donde hay heladas que matan muchas plantas o inhiben su crecimiento, seguidas de nueva vida en la primavera, que viene con un clima más cálido. Puede ser que esta visión "estándar" de la primavera sea la que prevalezca en México, pero no creo que sea la única. Por ejemplo, en el Distrito Federal es la época de más calor, antes de las primeras lluvias; $n$ ) en la segunda acepción de irlandés, debe decirse que es una lengua que pertenece a la rama céltica de la familia indoeuropea. También parece haber un error en la redacción. La frase "hablada por cerca de medio millón de personas" se presenta como si fuera acepción; debe seguir directamente después de "Lengua de Irlanda procedente del antiguo céltico"; o) bajo chocar y cortar, hace falta mención de los ritos infantiles para afirmar y cortar amistades. Consisten en decir "chócalas" y juntar la parte exterior de las primeras falanges de los puños en el primer caso, y en decir "córtalas" y hacer señas de tijeras con el índice y el cordial y hacer que se cortan entre sí, o hacer un círculo con el índice y el pulgar que el otro rompe, en el segundo.

Con respecto a las definiciones, hay una convención del diccionario que no se menciona en los preliminares pero que merece una presentación explícita. Además de la definición perifrástica, muchas entradas tienen, después de un punto y coma, una palabra, o a veces más, que es un cuasi sinónimo o que se puede usar como equivalente en el contexto dado. Éstos se dan para facilitar la comprensión de la definición larga para los lectores que conocen los equivalentes ofrecidos. Véase, como ejemplo, la entrada siguiente:

petaca $\mathrm{s} \mathbf{1}$ Recipiente de cuero o sintético en el que se lleva la ropa cuando sale uno de viaje; maleta, veliz 2 (Coloq) Nalga.

En este caso, maleta y veliz se ofrecen como equivalentes posibles de petaca después de haber dado una definición analítica. También se utiliza esta misma convención para indicar variantes orto- 
gráficas, como en el caso de huauzontle, citado arriba. Muchas veces estos sinónimos y variantes ortográficas no tienen sus propias entradas si es que son de muy baja frecuencia, una práctica con la cual, como ya comenté, no estoy de acuerdo. Convendría usar un signo distintivo para identificar las equivalencias y otro para las variantes puesto que el punto y coma es usual para separar partes en las definiciones perifrásticas, como ya se pudo notar en los ejemplos de azotea y huauzontle.

La organización de las definiciones en el DEUM es a partir de acepciones -entre las cuales se incluyen también locuciones lexicalizadas- que están organizadas, cuando es necesario, en tres niveles. Si no se encuentran "rasgos significativos comunes" (p. 18) entre las acepciones de lo que podría ser una sola palabra, entonces se consideran como acepciones de palabras distintas homófonas. En la práctica, este criterio tan estructuralista no parece ser determinante, sino algo como un concepto cognoscitivo de una red de relaciones que permite reunir varios significados, aun cuando es posible que algún par de ellos no tenga ningún rasgo significativo en común. Considérense las varias acepciones de paloma, por ejemplo, que incluyen 'tipo de pájaro', 'papalote', 'ayuda', 'cierta seña de aprobación', 'tipo de remate de cabeza en el futbol', 'persona inocente', 'tipo de cohete', 'maíz reventado en forma de flor' y 'órgano sexual' 19 . No me causa ningún disgusto verlas reunidas bajo una sola entrada. Quizás están relacionadas históricamente como extensiones metafóricas a partir del significado de la paloma como pájaro. Pero es difícil ver algún rasgo significativo compartido. También hay ejemplos de lo contrario. Hay dos entradas para quetzal; uno es el conocido pájaro de plumaje precioso que muere si está desprovisto de su libertad, y el otro es la unidad monetaria de Guatemala. En este caso la relación metonímica entre los dos significados es mucho más patente que la que podría existir entre los varios significados de paloma; el quetzal forma parte del escudo nacional de Guatemala y aparece en la moneda de ese país. ¿Por qué, entonces, se tratan como homónimos? En realidad, no es un problema grave; más que otra cosa refleja lo difícil del análisis semántico, y la complejidad del léxico y de las decisiones que los redactores han tenido que tomar a cada paso.

El criterio para la presentación de las acepciones, identificadas con números arábigos, también pretende ser totalmente sincrónico, a partir del significado identificado como estereotipo. Éste

${ }^{19}$ Éstas son mis glosas de la distintas acepciones, no las del DEUM. 
es el que "ha quedado más fijo en la memoria social y se muestra como base generadora de las acepciones subsecuentes" (p. 18). Suena bonito, pero no siempre es claro cómo se determina. Por ejemplo, bajo gustar, la primera acepción es su uso como verbo transitivo con el experimentador como sujeto - percibir el sabor de algo-, que ciertamente no es la más frecuente ni la más arraigada en la mente de los hablantes mexicanos. Las otras acepciones se presentan siguiendo un orden que pretende ser lógico, desde la más fija hasta la más metafórica. Cuando es conveniente, agrupan significados con números romanos. Puesto que el DEUM se basa en un estudio estadístico de un corpus, en mi opinión hubiera sido menos complicado, más objetivo, y más útil ordenar las acepciones de acuerdo con su frecuencia.

Las acepciones que aparecen en el diccionario vienen, en primer lugar, del corpus, pero no se limitan a las allí documentadas. Los editores han decidido "aumentar significados poco usuales pero importantes en México o para la comunicación internacional en la lengua española" (p. 17). De hecho, han completado la lista de acepciones de cada palabra a partir de su propio conocimiento como hablantes del español mexicano y después de tomar en consideración la documentación que han acumulado sobre ella. De todas maneras, es fácil encontrar acepciones usuales en México que no se incluyen en el DEUM. Por ejemplo, abdominal en el sentido de ciertos ejercicios (usado en un ejemplo bajo lagartija); ajonjolí o mole en la locución ajonjoli de todos los moles; ala y poste como posiciones en ciertos deportes; bola como un corte de carne; cara o niño en la locución cara de niño, un tipo de grillo; carta para referirse a cierto tamaño de papel u otras cosas relacionadas con él (cf. la entrada de cuartilla, donde se usa en este sentido); casual como informal; color para un lápiz de colores; chaparrera para la gordura excesiva en las piernas femeniles abajo de las caderas; churro en el sentido de chiripa y, con queso y gallo, en el sentido de un cigarro de mariguana; dona para un tipo de elástico anular para amarrar el pelo; ficha en el sentido de corcholata; filum para una agrupación lingüística; frijol o charro en la locución frijoles charros; hotel en la locución hotel de paso; jalar en el sentido de echar el agua de un excusado; ladrillo en el sentido de una pieza relativamente delgada que contrasta con tabique, y en el de un libro grande y pesado; losa para un colado de cemento en la construcción; mariscal de campo en el futbol americano; mota para la divisa que los escauts llevan en sus calcetines; no en la expresión no que (como en ${ }_{i}$ no que me ibas a llamar?); palo como pene; perfil para 
fierro que se usa en la construcción; pierna en el sentido de carne de pierna de puerco (como en torta de pierna); pino en el juego de boliche (usado en la entrada para boliche); pistola para el pene y en la expresión ser una pistola; puñal para un homosexual; salir, que, con la forma sale, se usa para expresar asentimiento o acuerdo sobre alguna decisión o plan; testigo en la locución testigo de Jehová; tío para un primo de los padres o para un amigo cercano o compadre de los padres; topo en el sentido de tuza; tres en su sentido numérico; tripa o gato en el nombre del juego tripas de gato. Me gustaría ver una discusión más pormenorizada de la fuente de las acepciones y los criterios para incluirlas o excluirlas.

Lo distintivo de este diccionario frente a otros y el grado en que el español de México está mal representado en otros diccionarios se nota especialmente en las acepciones del DEUM. Al hacer, una vez más, una cala en la letra $c h$, encontré muchas acepciones que no se registran en el DRAE, ni en el Larousse o en Santamaría: chalupa como receptáculo para instalaciones de electricidad; chamarra como bozal; chamizo como especie de árbol; chamorro como pierna de cerdo o para la pantorrilla bien formada de una mujer; chaqueta para la masturbación masculina; charrería para las actividades típicas de los charros; charro como tipo de pez y como traidor o corrupto; charrúa como originario de Uruguay; chi$c o$ en el sentido de enorme o para un vaso pequeño de pulque; chicote para el cable que opera ciertos mecanismos en un coche; chichi en el sentido de bebé; chile en la expresión de chile, de dulce y de manteca; la chilena como tiro de futbol; chimenea como cierta formación cilíndrica de minerales; chino en la locución estar algo en chino; chivas para palomitas de maíz; chocolate en la expresión como agua para chocolate; chocho como medicamento en homeopatía; chorizo para una cadena de objetos; chorro para la diarrea; chozno para el padre del tatarabuelo; chueco para tramposo, zurdo y cojo; y churro para rizo. Es decir, alrededor del $15 \%$ de las entradas tiene acepciones que no encuentro en los otros diccionarios que suelo consultar. El DRAE, en particular, no trae acepciones tan usuales como las de guarura como guardaespaldas, guinda como un color, estática como un tipo de ruido no deseado en los reproductores de sonido, birlo como tipo de tornillo, bitácora como tipo de cuaderno para registrar ciertos datos, cofre que tapa el motor del coche, o birria como tipo de comida.

Una característica del DEUM especialmente llamativa es el uso generoso de ejemplos para ilustrar sus palabras. Éstos son de dos tipos: los que van en letra cursiva y generalmente breves presentan 
algunas de las combinaciones más típicas de las palabras e ilustran, al mismo tiempo, características gramaticales de concordancia, selección, modificación y régimen. Otros, entrecomillados y más largos, comúnmente, pero no siempre, son tomados de manera directa del corpus u otras fuentes y sirven para documentar (pero no autorizar) el uso de la palabra. En general, me parecen muy bien elegidos. Frecuentemente son los mismos ejemplos de uso de las palabras que vienen a la mente de este lector. Junto con las muchas locuciones, dan al diccionario mucho de su sabor tan distintivamente mexicano. En algunos casos, ilustran usos o propiedades de las palabras que no se encuentran mencionados en otro lugar. Por ejemplo, bajo pick up se dice que es un sustantivo masculino, pero en el ejemplo se ve que también se puede tratar como femenino; y en la entrada de híjole, se encuentra la variante hijoles en un ejemplo.

Otro rasgo muy importante y útil es la inclusión de marcas de uso. El uso neutral y no marcado para el DEUM es el de la lengua estándar y culta, pero hay un amplio surtido de formas marcadas por ciertos registros sociales (literario, coloquial, popular, grosero, ofensivo, caló, rural), por un buen número de campos científicos o técnicos (arquitectura, botánica, marinería, tauromaquia, etc.), por algunos géneros específicos (científico, periodístico) o por distintas variedades regionales (altiplano central, Baja California, sur de Veracruz, norte etc.) que también han sido incluidas ${ }^{20}$. Estas designaciones surgen de los estudios de dispersión de las palabras en el corpus original, avalados y desarrollados por el mismo equipo de redacción. De esta manera se puede apreciar qué tan apropiada es una palabra dada en cierto contexto. Gracias a este tipo de información, descubrí finalmente, pero demasiado tarde, que pinche y carajo son groseros, pero canijo es simplemente popular. Para los extranjeros que hablan el español de otras regiones donde los juicios afectivos no necesariamente corresponden a los de México, estas marcas podrían ser útiles para evitar malentendidos. El guatemalteco puede ver que pisar, por ejemplo, no es grosero en México pero que quizás sería más prudente hablar de colorín en lugar de palo pito. En algunos casos, me parece que hacen falta marcas de uso en palabras que se dan como neutrales. Por ejemplo, huéhuetl, tlatoani y pipiltin no tienen marca alguna

${ }^{20}$ En gran parte esto es lo que da al DEUM su personalidad distintiva frente a los primeros dos productos del proyecto puesto que éstos sólo pretendían incluir lengua culta estándar. 
pero son palabras nahuas usadas como términos técnicos para hablar de la cultura mexicana prehispánica.

El aparato gramatical del DEUM se mantiene en un mínimo. Para cada entrada y, cuando es necesario, para las acepciones, se da la categoría gramatical en términos muy generales: adjetivo, adverbio, artículo, conjunción, interjección, participio, preposición, pronombre, sustantivo (masculino, femenino; singular, plural), verbo (transitivo, intransitivo, pronominal) ${ }^{21}$. Además, para los verbos se indica el modelo para su conjugación que corresponde a uno de los treinta y seis paradigmas modelo que se dan en los preliminares (pp. 37-50). En algunos casos se da más información -por ejemplo, el hecho de que el verbo consistir generalmente va seguido de la preposición en-, pero lo más común es que cualquier otro dato se tiene que sacar de los ejemplos de uso, los cuales no siempre son suficientes para resolver posibles dudas.

Información adicional es especialmente importante para el manejo correcto de los verbos. Muchas de mis consultas a los diccionarios son para ver cómo éstos se construyen con sus argumentos y cuáles son las preposiciones que deben emplearse; las más de las veces los diccionarios fallan en este punto. El DEUM sufre del mismo problema. Hay entradas donde los ejemplos sí me parecen adecuados para resolver dudas de este tipo; así es en el caso de depender, donde se ve que siempre va acompañado da la preposición de. Pero con sustituir, la definición da la impresión de que el objeto directo va a ser el sustituto o la cosa nueva. Sin embargo, uno de los ejemplos pone la cosa nueva como sujeto y la cosa sustituida como objeto directo, mientras que otro pone la cosa sustituida como objeto directo y la cosa nueva como circunstancial con la preposición con. No hay nada que indique que la cosa nueva no puede ser objeto directo (lo cual sería mi inclinación automática como anglohablante), ni tampoco hay indicio de que la cosa nueva puede ser indicada con la preposición por ( sustituyó la almohada por una colcha). Lo mismo pasa con cargar. No hay suficiente información como para saber que el objeto directo puede ser tanto el objeto colocado como el lugar donde algo se coloca y que el otro elemento se puede expresar como circunstancial: cargó la leña al burro o cargó el burro con leña. En un futuro,

${ }^{21}$ En general, la aplicación de estas etiquetas no provoca problemas. He notado un caso, sin embargo, donde la clasificación gramatical me sorprendió. Clasifica a aun en el sentido de 'hasta, incluso' como una preposición cuando parece ser más bien un adverbio. 
sería bueno pensar en sistematizar la información sobre la realización sintáctica de los papeles semánticos asociados con los verbos y, en su caso, con otras clases de palabras ${ }^{22}$.

Otro tipo de información gramatical que no recibe suficiente atención, en mi opinión, es la forma plural de los sustantivos, sobre todo los sustantivos recientemente tomados prestados del inglés. Por ejemplo, ¿es el plural de hall, halls o halles? ¿Y de bat, club, clutch, clóset, sándwich, sócket, shock, short, show, etc.? todas son palabras donde yo personalmente tengo dudas y quisiera saber cuál es la forma usual en México; pero el DEUM no dice nada al respecto. Una posibilidad sería dar una regla general en los preliminares y sólo proporcionar información explícita en los casos excepcionales.

Hay otros puntos gramaticales que merecerían más atención en la Introducción. Por ejemplo, la formación de diminutivos. En general, estas formas, y los aumentativos, no reciben tratamiento aparte sino que aparecen en los ejemplos de uso si es que van a aparecer. Pero es bien sabido que hay variación regional en el uso de estas formas en el mundo hispanohablante y valdría la pena ser más sistemático en su trato y decir algo sobre su uso en México. ¿Cómo sabrá el usuario que el diminutivo de mano es manita y no manito, pero que el diminutivo de mapa no es mapito sino mapita? ¿O si el diminutivo usual de lejos es lejitos o lejecitos? ¿O dónde se dice patito y dónde patico?

Lo mismo pasa con las formas flexivas no estándares. Hay lugares en México - Chiapas y Tabasco-donde todavía vosean algunas personas, pero ni en los paradigmas de los verbos ni en algún otro lugar se hace referencia a este fenómeno. Y las formas verbales de la segunda persona singular del pretérito con una $s$ al final (p. ej. fuistes) son muy frecuentes en México, pero tampoco reciben mención. En el paradigma de haber no hay señas de haiga y en el ver la ausencia de vide es notoria. En fin, hace falta una política explícita frente a este tipo de ejemplos. Llama la atención en especial el paradigma de venir (p. 48) donde se listan las formas pretéritas vinimos y viniste cuando la norma mexicana, a diferencia de la norma peninsular, pide, o por lo menos permite, venimos y veniste según Williamson (op. cit., p. 124).

${ }^{22}$ Véase, por ejemplo, el diccionario que editan Vox y la Universidad de Alcalá de Henares mencionado arriba, que pretende registrar, sistemáticamente, información sobre el régimen preposicional de los verbos y los tipos de complementos que permiten. 
Un aspecto interesante de este diccionario es el manejo de la ortografía de préstamos. Pretende reflejar el uso preferido en la imprenta mexicana, que generalmente es el de mantener la ortografía original. Cuando hay varias grafías alternas, se presentan, en principio, las menos frecuentes como entradas secundarias (p. 15). Es una práctica correcta y deben rectificarse los muchos casos donde no se hace. Véase, por ejemplo, socket, donde su variante sóquet no tiene entrada; y cenzontle, donde su variante sinsonte, mencionada bajo la variante zenzontle en lo que debe ser una entrada secundaria que simplemente remite a la primaria, tampoco tiene entrada.

El hecho de preservar la ortografía no hispánica en varios casos implica que la pronunciación de estas palabras no siempre es evidente. Por lo tanto, el diccionario también da la pronunciación en estos casos, utilizando, con dos excepciones, la ortografía estándar del español. La primera excepción es que en algunos casos emplea $<$ sh $>$ para representar el fenomeno $<\check{\text { s }}>$, el cual, por cierto, no se incluye en la sección sobre "Reglas de ortografía y puntuación" (cf. la entrada de beige). También hay casos -la segunda excepción-donde se incluye un acento gráfico donde no es necesario. Por ejemplo, la pronunciación de pick up se da como picóp, y una de las pronunciaciones de jersey se da como yérsi. En mi opinión, estas formas que se dan para indicar la pronunciación se deben interpretar, además, como una propuesta de una ortografía hispánica normalizada y, por lo tanto, los acentos gráficos que no sean requeridos por las reglas ortográficas del español deben eliminarse. También hay formas donde convendría dar una pronunciación pero no se hace. Estoy pensando sobre todo en palabras que contienen una $<\mathrm{x}\rangle$. Por ejemplo, ¿cómo saber que mixe se pronuncia como mije y que ixtle se pronuncia como istle? Por otra parte, hay casos como smog, boiler, bunker, thinner y sandwich que no se pronuncian como se escriben pero sin una aclaración al respecto.

En general el manejo de la ortografía me parece razonable, con la excepción del uso de los acentos gráficos. Según la Introducción, "las palabras extranjeras o los extranjerismos se asimilan a las reglas de acentuación del español" (p. 33), pero este principio no se aplica en el diccionario e inclusive existen contradicciones. Se dice que currículum sigue esta tendencia (p. 33), pero en la entrada correspondiente no lleva acento, lo que, de hecho, es normal en la práctica cotidiana que he podido observar. En mi opinión se debe marcar el acento en cualquier palabra que de otra 
manera no se pronunciaría bien, según las reglas generales de la ortografía española, y que no tenga una indicación explícita de su pronunciación.

El diccionario tiene una sección en los preliminares, "Reglas de ortografía y puntuación" (pp. 27-36), que es la parte más débil de la obra. Sobre ortografía, se presenta una lista de los fonemas del español y las letras utilizadas para representarlos, seguida por una lista de las letras que tienen complicaciones en su uso y una descripción de cuándo se emplean. Hay fonemas que no aparecen $(/ 1 /, / \mathrm{sh} /)$; las descripciones del empleo de las letras no son muy completas (por ejemplo, al hablar del uso de la $<\mathrm{c}>$ para representar el sonido $/ \mathrm{k} /$, no se menciona la posición implosiva, como en octubre, tic, técnico, etc.) o equivocadas (comparando la $u$ con la $\ddot{u}$, dice la $\ddot{u}$ se utiliza seguida de $e, i$; pero la $u$ también se puede usar antes de estas mismas vocales); no dice que cuando la $<\mathrm{i}>$ o la $<\mathrm{u}>$ están al principio de un diptongo o triptongo en la primera sílaba de una palabra sin consonante antes en la pronunciación, se requiere, con muy pocas excepciones, una $<\mathrm{h}>$ para iniciar la palabra gráficamente; xocoyote se da como ejemplo de la $x$ con valor de /s/ como de /šs/; etc. En mi opinión sería mejor separar dos fenómenos y describir cada uno sistemáticamente. De un lado, dar todos los fonemas y para cada uno explicar la manera de representarlo gráficamente. Del otro, dar todas las letras y describir los sonidos que pueden representar.

En la descripción de la acentuación, no trata el uso del acento gráfico con palabras interrogativas como casos de acento diacrítico; dice que últimamente es un ejemplo de una palabra sobreesdrújula; no menciona la optatividad de algunos acentos diacríticos; etc. En cuanto a la puntuación, hay menos problemas. De todas maneras, sería aconsejable señalar la puntuación de números y de la notación de la hora; son dos áreas donde hay mucha variación en el mundo hispanohablante y donde convendría registrar precisamente el uso mexicano.

También requiere más atención el uso de mayúsculas. En las "Reglas de ortografía y puntuación", este tema no se menciona. En el texto, hay algunas referencias, pero no son sistemáticas. Por ejemplo, bajo sor, se dice que se escribe generalmente con mayúscula, pero bajo san, no se dice nada en cuanto al uso de altas y bajas, aunque la práctica normal parece ser la misma que en el caso de sor.

El DEUM es puramente sincrónico. No da etimologías ni tampoco menciona el origen de préstamos o ámbitos de uso fuera de 
México con etiquetas como anglicismo, galicismo, españolismo, etc. Sólo hay una excepción, que menciono porque me parece que no se maneja consistentemente. En algunos casos se nota que una palabra es una forma truncada (como prepa, fray) o un acrónimo ( $\operatorname{sida}$ ), mientras que en otros, no se dice nada al respecto ( migra, mano, ñero, auto, radio, metro, radar, priista).

Este diccionario también excluye todo tipo de apoyo extralingüístico, como cuadros, diagramas, fotografías, dibujos, etc. Las únicas excepciones son tres cuadros al final con "Escritura de los números", "Gentilicios de la República mexicana”, y "Gentilicios de los países hispanoamericanos". Por el momento esta decisión me parece buena en el sentido de que obliga a buscar definiciones totalmente autónomas y puramente lingüísticas. La única excepción que he notado es el uso de algunos signos no alfabéticos que se utilizan en la lengua escrita y que aparecen en el texto. Por ejemplo, los signos de más $(+)$, menos $(-)$, y por $(\times)$ aparecen en las definiciones de las palabras correspondientes (véanse también factorial, paloma, grado, porciento, igual). Creo que esta práctica se debe generalizar más, tanto para signos específicos (por ejemplo, el de entre $[\div]$, raíz cuadrada $[\sqrt{ }]$ minuto ['], segundo

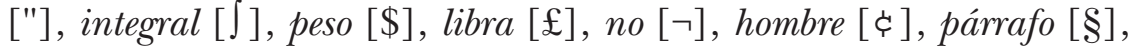
corazón $[\bullet]$, los números naturales, etc.) como para ciertas combinaciones y abreviaturas (como la manera para señalar y leer logaritmos, longitud y latitud, fracciones, división, la hora, la fecha, etc.). También recomiendo juntar los signos y expresiones no alfabéticos, o que no se pueden encontrar en el orden normal del diccionario como entradas, en un cuadro con sus nombres y/o lecturas. En cambio, las abreviaturas y expresiones puramente alfabéticas se deben incluir como entradas $(h, l o g, m, k g$, etc.) o, por lo menos, en el cuadro de abreviaturas (pp. 9-10). Actualmente muchas de ellas únicamente se encuentran en la entrada de la palabra de la cual forman una abreviatura. Es de notar que existen varias abreviaturas comunes que no están mencionadas en el diccionario y que convendría agregar, por ejemplo, las de número, hora, página, editor, los meses, etcétera.

A pesar de la renuencia de los editores a incluir elementos no lingüísticos en el diccionario, sería conveniente agregar algunos cuadros adicionales como apoyo al usuario. Por ejemplo, me gustaría ver un resumen de los prefijos del sistema métrico y un mapa de la República mexicana para poder ubicar los pueblos y estados mencionados y, en particular, las zonas donde se usan los regionalismos. Recomiendo, además, un cuadro de nombres de pila y 
los apodos correspondientes usuales en México, puesto que el diccionario no incluye nombres propios y los apodos pueden variar considerablemente de país a país.

A lo largo del DEUM se percibe una actitud imparcial y descriptiva admirable. Esta característica se nota, por ejemplo, en las definiciones de conceptos religiosos, las cuales no presuponen una religión particular del lector. También se nota en la inclusión de formas no estándares, como onde y pos aunque otras, como nadien, entós, pus y pérate no se encuentran. El diccionario no asume el papel de censor; más bien deja la decisión de usar cierta palabra o no a la discreción de los usuarios. Su único compromiso es el de proporcionar información adecuada y precisa sobre el significado social de las palabras. Hablando de las groserías, los editores dicen que "Cada quien sabe y decide si las usa o no" (p. 20). Sólo he notado un lugar donde se les escapa un comentario más normativo. En la entrada de ahíse dice que frecuentemente se acentúa la $a$ en la lengua hablada y que este hecho "llega incluso a reflejarse en la lengua escrita cometiendo ciertos errores o faltas" (p. 85). Hubiera sido más consistente con las líneas generales del diccionario reconocer otra palabra o variante, ahi (o mejor ay), e identificarla como coloquial, o simplemente tratarla como otros casos de acento variable (periodo/periodo, zaino/zaino, etc.).

Finalmente, puedo mencionar que la edición es atractiva. Se nota que se cuidó mucho y que hay muy pocas erratas ${ }^{23}$. Es de un tamaño fácil de manejar y de una tipografía chica pero cómoda para la consulta. Los pliegos están cosidos y por lo tanto el libro debe aguantar un uso intensivo, aunque con toda la manipulación para preparar esta reseña, el último cuaderno de mi ejemplar se desprendió. Quizás se debe contemplar una edición empastada.

En conclusión, el Diccionario del español usual en México es una obra bien hecha y extremadamente rica que debe ser juzgada por lo que contiene, no por lo que no contiene. Será una gran ayuda para los viajeros que pasan por México y para cualquier estudiante de cosas mexicanas. Aun más, es un emblema de lo que es ser mexicano y hablar como mexicano, y cumple así la importante función ideológica de los diccionarios monolingües ${ }^{24}$. Finalmente, es una muy buena muestra de ese arte verbal que condujo a fray

${ }^{23}$ Hacen falta dos comillas dobles para cerrar las dos citas en auto ${ }^{1}$, y omnivoro se escribe mal bajo cucaracha.

${ }^{24}$ L. F. LARA, "El diccionario, instrumento de la etnicidad", Dimensiones de la lexicografía. A propósito del "Diccionario del español de México", pp. 39-50. 
Juan Bautista a declarar, hace casi cuatrocientos años, que "casi vniuersalmente todas las gentes destas Indias tienen natural eloquencia ( $\mathrm{y}$ assí les es fácil orar y representar sus bienes y sus males: como si todas las reglas y colores de la Rethórica vuiesen aprendido, y embeuido en sí toda su vida co[n]forme al arte) mayormente las Mexicanas" 25 . Aunque estos mexicanos hablaban náhuatl y no español, el DEUM da amplio testimonio de que la elocuencia natural a la que se refiere sigue viva ${ }^{26}$.

Thomas C. SMith

El Colegio de México

${ }^{25}$ Hvehvetlahtolli, M. Ocharte, México, 1600; ed. facs. publ. como Libro de los huehuehtlahtolli[;] testimonios de la antigua palabra, con est. introd. de M. León-Portilla y vers. de los textos nahuas por L. Silva Galeana, Comisión Nacional Conmemorativa del V Centenario del Encuentro de Dos Mundos, México, 1988, f. 92r.

${ }^{26}$ Quisiera expresar mi agradecimiento a los miembros del equipo lexicográfico del DEUM por haber discutido varios aspectos de su diccionario conmigo y por haber leído versiones preliminares de esta reseña. Me hicieron muchas observaciones que han permitido mejorarla. También recibí ayuda sobre varios puntos de redacción y contenido de Maripaz Covarrubias, Martha Elena Venier, Pedro Martín Butragueño y de mis hijas Sandra y Ana, la cual les agradezco. 